\title{
Effect of the Screw Torque Level on the Interfragmentary Strain and the Interfragmentary Modulus
}

\begin{abstract}
Boonthum Wongchai
Department of Mechanical Engineering, Faculty of Engineering at Si Racha, Kasetsart University, 199 M.6, Tungsukhla, Si Racha, Chonburi, 20230, Thailand

Received 2012-12-30, Revised 2013-05-22; Accepted 2013-07-13

ABSTRACT

The screw torque is applied at the screw head to fix the plate and the bone. It generates the compressive force between the plate and the bone to stabilize them. The interfragmentary strain is the main factor for healing the bone fractured. The screw torque level affects the interfragmentary strain and the stability of the fixation between the plates an the bone. The interfragmentary modulus is the new factor of the plate fixation stability and it is affected by the torque level. This research is proposed to study the effect of the screw torque level on the interfragmentary strain and the interfragmentary modulus. The interfragmentary strain and the interfragmentary modulus decrease by increasing the screw torque level.
\end{abstract}

Keywords: Screw Torque Level, Interfragmentary Strain, Interfragmentary Modulus, LC-DCP, Limited Contact Dynamics Compression Plate, Femur Fracture

\section{INTRODUCTION}

Internal fixation is the main method to cure the human bone fracture (Wahnert et al., 2012). The plate fixation is the main choice of the internal fixation. The Dynamic Compression Plate (DCP) and the Limited Contact Dynamics Compression Plate (LC-DCP) are generally used to fix the broken bone. For the DCP, only the conventional screws are used. The conventional screws fix the plate and the bone by the compressive force that is generated by the applied torque at the screw head (Kanchanomai et al., 2008; Field et al., 2004; Kabak et al., 2004; Gao et al., 2011; Kumar et al., 2013). For the LCDCP, the locking screws are used to make the distance between plate and bone. The conventional screw can be used in the LC-DCP as the DCP.

The contact between the plate and the femur affects the periosteal blood supply to the femur (Haasnoot et al., 1995; Ahmad et al., 2007). The LC-DCP is developed to solve this problem by using the locking screws (Borgeaud et al., 2000; Field et al., 2004; Kabak et al., 2004; Miller and Goswami, 2007).

However, the stability of the plate and the bone must be conscious. The plate fixation with the conventional screws has more stable than the locking screws because the locking screw cannot generates the compressive force (Haasnoot et al., 1995; Ahmad et al., 2007; Kumar et al., 2013).

In the human bone fracture, the screw tensile force (internal force) ranges from $2000 \mathrm{~N}$ to $3000 \mathrm{~N}$ (Kim et al., 2010). Ahmad et al. (2007) applied the screw torque of 4 $\mathrm{N} \cdot \mathrm{m}$ in their research.

The interfragmentary strain $\left(\varepsilon_{\mathrm{IF}}\right)$ is a main factor of femur fractured healing. It has the best ranges from 2$10 \%$ (Perren, 1979; Kim et al., 2010). It is defined as the ratio of the fracture gap displacement after the body load applied and the original fracture gap as shown in Fig. 1.

The Equation (1) of $\varepsilon_{\mathrm{IF}}$ is:

$\varepsilon_{\mathrm{IF}}=\frac{\Delta \mathrm{L}}{\mathrm{L}}$

$\Delta \mathrm{L}=$ The fracture gab displacement after the body load (W) applied

$\mathrm{L}=$ The original fracture gap length $(\mathrm{L}=10 \mathrm{~mm}$ for this study)

The physician will cut the fracture and form a gap of 1$10 \mathrm{~mm}$ when the fracture occurs at the middle part of the femur. In this present work, a gap of $10 \mathrm{~mm}$ was applied. 
The normal stress in the plate at the fracture gab is the combine stress from the normal stress and the bending stress (Fouad, 2011). For the normal stress, the equation of the normal stress can be written as Equation (2):

$\sigma_{\mathrm{IF}}=\frac{\mathrm{W}}{\mathrm{A}}$

Where:

$\sigma_{\mathrm{IF}}=$ Normal stress or interfragmentary stress

$\mathrm{W}=$ Body load

$\mathrm{A}=$ Plate cross section area

The equation of the bending stress is Equation (3):

$\sigma_{\mathrm{b}}=\frac{\mathrm{My}}{\mathrm{I}}$

$\mathrm{M}=$ Bending moment $=\mathrm{We}(\mathrm{e}=$ distance from the body load to the centroid of the plate cross section area)

$\sigma_{\mathrm{b}}=$ Bending stress

$\mathrm{y}=$ The distance from the centoid of the plate cross section area

$\mathrm{I}=$ Moment of inertia of the plate cross section area

Wongchai (2012) has defined the Interfragmentary Modulus (IM) as the slope of the graph between $\sigma_{\mathrm{IF}}$ and $\varepsilon_{\mathrm{IF}}$ when the are linearity related. The relation between $\sigma_{\mathrm{IF}}$ and $\varepsilon_{\mathrm{IF}}$ can be written as Equation (4):

$\sigma_{\mathrm{IF}}=\mathrm{IM} \varepsilon_{\mathrm{IF}}+\mathrm{k}$

$\mathrm{k}=$ Constant value

In the present work, the interfragmentary strain and the interfragmentary modulus is the goal to study at various bone screw torques level.

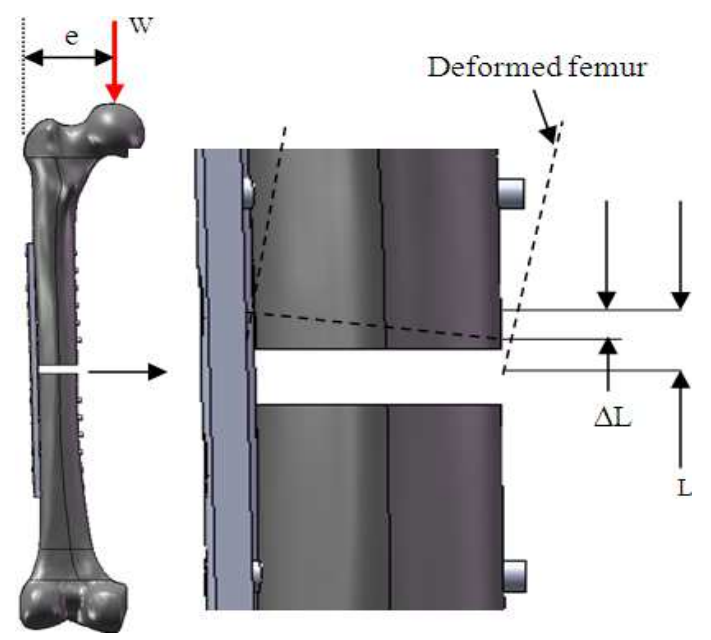

Fig. 1. The deformation of the fractured femur

\section{MATERIALS AND METHODS}

The 3406 large left fourth generation femur of Pacific Research Lab is used in the present work. The Pacific research laboratories bone are usually used in biomechanics research (Greer and Wang, 1999; Stoffel et al., 2003; Ahmad et al., 2007). The 12-holes LC-DCP from synthes Inc. with the ten conventional screws are attached on the femur.

The $10 \mathrm{~mm}$ gap is generated at the middle point of the femur. The Kyowa DTC-A-5 clip-type displacement transducer with specification listed in Table 1 is used to measure $\Delta \mathrm{L}$.

The lowest of the femur is fixed with epoxy resin while the femur head is fixed by one bolt as shown in Fig. 2. The jig at the femur head can be rotated about this bolt and touched the femur head for transferring the compressive force from the compressive testing machine.

The compressive force from the compression testing machine and displacement signals are converted to digital signals by the Kyowa PCD-300A. The PCD-300A software is used for data recording.

Table 1. Displacement transducer specification

\begin{tabular}{ll}
\hline Rated capacity & $\begin{array}{l}5 \mathrm{~mm}(\text { mounting groove } \\
\text { interval } 4 \text { to } 9 \mathrm{~mm})\end{array}$ \\
\hline Rated output & $2.5 \mathrm{mV} / \mathrm{V}\left(5000 \times 10^{-6}\right.$ strain $)$ \\
Non-linearity & $\pm 1 \% \mathrm{RO}$ or better \\
Hysteresis & $\pm 1 \% \mathrm{RO}$ or better \\
Repeatability & $\pm 1 \% \mathrm{RO}$ or better \\
Recommended bridge voltage & 2 to $4 \mathrm{~V}, \mathrm{AC}$ or $\mathrm{DC}$ \\
Safe bridge voltage & $10 \mathrm{~V}, \mathrm{AC}$ or DC \\
Input resistance & $350 \Omega \pm 2 \%$ \\
Output resistance & $350 \Omega \pm 2 \%$ \\
\hline
\end{tabular}

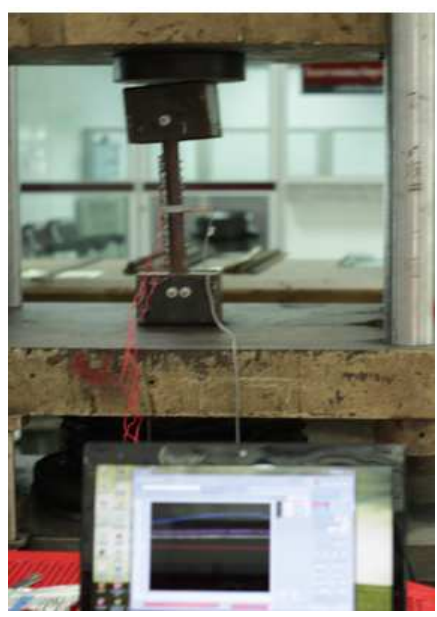

Fig. 2. The experiment setup 


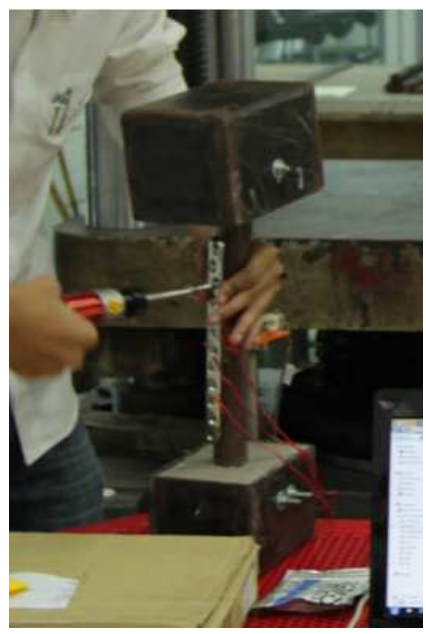

Fig. 3. The bone screw torque setting

Figure 3 shows the torque applyed on the screw head. The level of the screw torque is varies from 1 to 5 N.m. The compressive force $F$ on the femoral head is varies from 0 to $300 \mathrm{~N}$.

\section{RESULTS}

The graphs of $\varepsilon_{\mathrm{IF}}$ versus the compressive force for all cases of the screw torque level are shown in Fig. 4.

By using the Equation (2) and (4), the graphs of $\sigma_{\mathrm{IF}}$ versus $\varepsilon_{\mathrm{IF}}$ for all cases of the screw torque level are shown in Fig. 5.

The relations between $\varepsilon_{\mathrm{IF}}$ and $\mathrm{F}$ are generated by using the linear regression in Equation (5):

$\varepsilon_{\mathrm{IF}}=\mathrm{aF}+\mathrm{b}$

Where:

\section{$\mathrm{a}, \mathrm{b}=$ Constant}

The results of $a$ and $b$ with $\mathrm{R}^{2}$ are in Table 2. By using Equation (4), IM and $\mathrm{k}$ are calculated and shown in Table 3.

\section{DISCUSSION}

From Fig. 4, it has been found that the slopes of the graph decreased by increasing the screw torque level. In other words; for the same compressive force applied at the femoral head, the interfragmentary strain decreased when the screw torque level is increased.

From the data in Table 2, It has been seen that the relation between $\varepsilon_{\mathrm{IF}}$ and $\mathrm{F}$ is the linear function with high $\mathrm{R}^{2}$ because the plate, the femur and the screws are linear materials. In the present work, the applied force at the femur head is not exceeding the elastic limit of all parts.

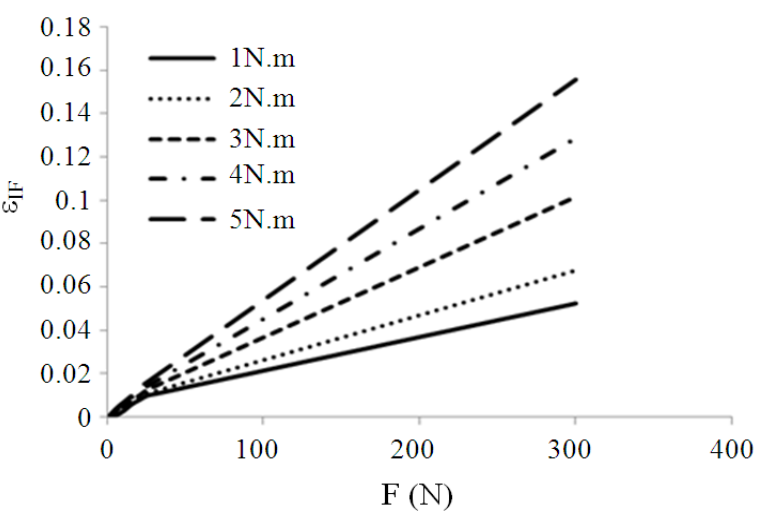

Fig. 4. The correlation between $\varepsilon_{\mathrm{IF}}$ and $\mathrm{F}$

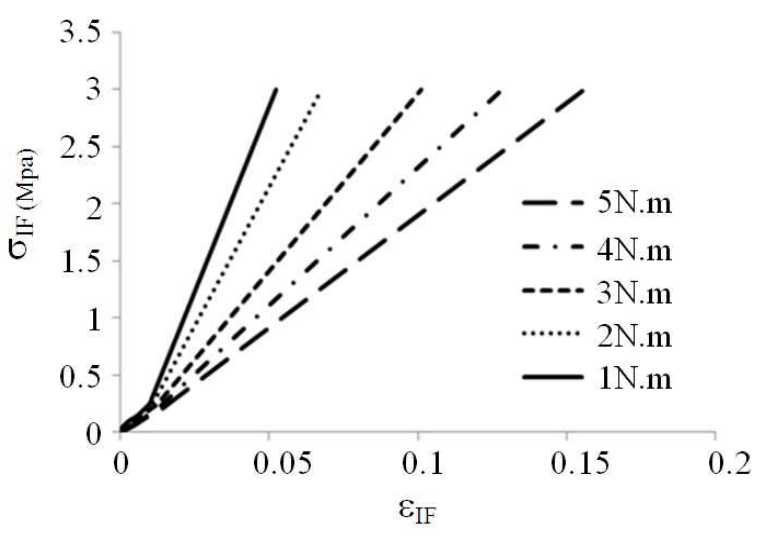

Fig. 5. The correlation between and $\varepsilon_{\mathrm{IF}}$

Table 2. Correlation constants for $\varepsilon_{\mathrm{IF}}$

\begin{tabular}{llll}
\hline $\begin{array}{l}\text { Bone screw torque } \\
(\mathrm{N} . \mathrm{m})\end{array}$ & $\mathrm{a}$ & $\mathrm{b}$ & $\mathrm{R}^{2}$ \\
\hline 1 & 0.00154 & 0.00613 & 0.993 \\
2 & 0.00206 & 0.00589 & 0.996 \\
3 & 0.00322 & 0.00463 & 0.999 \\
4 & 0.00415 & 0.00397 & 0.999 \\
5 & 0.00507 & 0.00356 & 0.999 \\
\hline
\end{tabular}

Table 3. IM and k

\begin{tabular}{llll}
\hline $\begin{array}{l}\text { Bone screw torque } \\
(\mathrm{N} . \mathrm{m})\end{array}$ & $\mathrm{IM}$ & $\mathrm{k}$ & $\mathrm{R}^{2}$ \\
\hline 1 & 61.88 & -0.292 & 0.993 \\
2 & 47.05 & -0.216 & 0.996 \\
3 & 36.62 & -0.113 & 0.999 \\
4 & 23.90 & -0.079 & 0.999 \\
5 & 19.62 & -0.059 & 0.999 \\
\hline
\end{tabular}


The graphs of the $\varepsilon_{\mathrm{IF}}$ and $\mathrm{F}$ must be stayed in the elastic zone of material (linear zone).

Table 3 shows that the relations between $\sigma_{\mathrm{IF}}$ and $\varepsilon_{\mathrm{IF}}$ are linear with high $\mathrm{R}^{2}$. The slope (IM) of the graphs in Fig. 5 decreased when the screw touque level is increased. Because the meaning of IM is the spring stiffness and the stabilliy of the bone-plate fixation. Thus, the stabilliy of the bone-plate fixation decresed when the screw touque level is increased.

\section{CONCLUSION}

- The interfragmentary strain decreased by increasing the screw torque level

- The interfragmentary modulus decreased by increasing the screw torque level

\section{ACKNOWLEDGEMENT}

The researcher is grateful to Kasetsart University, $\mathrm{Si}$ Racha Campus and the Center for Advanced Studies in Industrial Technology for the research grants.

\section{REFERENCES}

Ahmad, M., R. Nanda, A.S. Bajwa, J. Candl-Couto and S. Green et al., 2007. Biomechanical testing of the locking compression plate: When does the distance between bone and implant significantly reduce construct stability? Injury, 38: 358-364. DOI: 10.1016/j.injury.2006.08.058

Borgeaud, M., J. Cordey, P.F. Leyvraz and S.M. Perren, 2000. Mechanical analysis of the bone to plate interface of the LC-DCP and of the PC-FIX on human femora. Injury, 31. 29-36. PMID: 11052378

Field, J.R., R. Edmonds-Wilson and R.M. Stanley, 2004. An evaluation of interface contact profiles in two low contact bone plates. Injury, 35: 551-556. DOI: 10.1016/S0020-1383(03)00215-8

Fouad, H., 2011. Assessment of function-graded materials as fracture fixation bone-plates under Combined loading conditions using finite element modelling. Med. Eng. Phys., 33: 456-463. DOI: 10.1016/j.medengphy.2010.11.013

Gao, M., W. Lei, Z. Wu, D. Liu and L. Shi, 2011. Biomechanical evaluation of fixation strength of conventional and expansive pedicle screws with or without calcium based cement augmentation. Clin. Biomech., 26: 238-244. DOI: 10.1016/j.clinbiomech.2010.10.008
Greer, B. and E.L. Wang, 1999. Solid model in IGES format.

Haasnoot, E.V.F., T.W.H. Miinch, P. Matter and S.M. Perren, 1995. Radiological sequences of healing in internal plates and splints of different contact surface to bone. (DCP, LC-DCP and PC-Fix). Injury, 26: B28-B36. DOI: 10.1016/00201383(95)96896-C

Kabak, S., M. Halici, M. Tuncel, L. Avsarogullari and S. Karaoglu, 2004. Treatment of midclavicular nonunion: Comparison of dynamic compression plating and low-contact dynamic compression plating techniques. J. Shoulder Elbow Surgery, 13: 396-403. DOI: $10.1016 /$ j.jse.2004.01.033

Kanchanomai, C., V. Phiphobmongkol and P. Muanjn, 2008. Fatigue failure of an orthopedic implant-A locking compression plat. Eng. Failure Anal., 15: 521-530. DOI: 10.1016/j.engfailanal.2007.04.001

Kim, S.H., S.H. Chang and H.J. Jung, 2010. The finite element analysis of a fractured tibia applied by composite bone plates considering contact conditions and time-varying properties of curing tissues. Compos. Struct., 92: 293-2118. DOI: 10.1016/j.compstruct.2009.09.051

Kumar, V., D. Mehrotrab, S. Mohammadc, R.K. Singhb and V. Singhd et al., 2013. Anchor lag screw vs conventional lag screw in mandibular fractures: A series of 30 cases. J. Oral Biol. Craniofacial Res., 3: 15-19. DOI: 10.1016/j.jobcr.2013.01.002

Miller, D.L. and T. Goswami, 2007. A review of locking compression plate biomechanics and their advantages as internal fixators in fracture healing. Clin. Biomech., 22: 1049-1062. DOI: 10.1016/j.clinbiomech.2007.08.004

Perren, S.M., 1979. Physical and biological aspects of fracture healing with special reference to internal fixation. Clin. Orthop. Relat. Res., 138: 175-196. PMID: 376198

Stoffel, K., U. Dieter, G. Stachowiak, A. Gachter and M.S. Kuster, 2003. Biomechanical Testing of the LCP- how can stability in locked internal fixators be controlled? Injury, 34: 11-19. DOI: 10.1016/j.injury.2003.09.021

Wahnert, D., J.H. Lange, M. Schulze, S. Lenschow and R. Stange et al., 2012. The potential of implant augmentation in the treatment of osteoporotic distal femur fractures: A biomechanical study. Injury, 44: 808-812. DOI: 10.1016/j.injury. 2012.08.053

Wongchai, B., 2012. Interfragmentary modulus. Am. J. Applied Sci., 9: 372-375. DOI: 10.3844/ajassp.2012.372.375 